\title{
Article \\ Nanoporous Co and N-Codoped Carbon Composite Derived from ZIF-67 for High-Performance Lithium-Sulfur Batteries
}

\author{
Songqiao Niu, Chenchen $\mathrm{Hu}$, Yanyu Liu, Yan Zhao * and Fuxing Yin * \\ School of Materials Science and Engineering, Hebei University of Technology, Tianjin 300130, China; \\ n2642275274@163.com (S.N.); h15364966537@163.com (C.H.); 18331525609@163.com (Y.L.) \\ * Correspondence: yanzhao1984@hebut.edu.cn (Y.Z.); yinfuxing@hebut.edu.cn (F.Y.)
}

Citation: Niu, S.; Hu, C.; Liu, Y.;

Zhao, Y.; Yin, F. Nanoporous Co and $\mathrm{N}$-Codoped Carbon Composite Derived from ZIF-67 for

High-Performance Lithium-Sulfur Batteries. Nanomaterials 2021, 11, 1910. https://doi.org/10.3390/nano11081910

Academic Editor: Christian M. Julien

Received: 20 June 2021

Accepted: 14 July 2021

Published: 25 July 2021

Publisher's Note: MDPI stays neutral with regard to jurisdictional claims in published maps and institutional affiliations.

Copyright: (C) 2021 by the authors Licensee MDPI, Basel, Switzerland. This article is an open access article distributed under the terms and conditions of the Creative Commons Attribution (CC BY) license (https:/ / creativecommons.org/licenses/by/ $4.0 /)$.

\begin{abstract}
Lithium-sulfur (Li-S) batteries have nice prospects because of their excellent energy density and theoretical specific capacity. However, the dissolution of lithium polysulfides and shuttle effects lead to a low coulombic efficiency and cycle performance of Li-S batteries. Therefore, designing electrode materials that can suppress the shuttle effect and adsorb polysulfides is of great significance. In this work, a Co and N-codoped carbon composite via heating a type of Co-etched zeolitic imidazolate framework-67 (ZIF-67), nanocube precursor, in inert gas is reported as a cathode sulfur carrier material for Li-S batteries. The experimental results show that high-temperature carbonization results in mesoporous structures inside the material which not only provide ion channels for the reaction but also improve the adsorption capacity of polysulfides. Furthermore, the exposed metal Co sites and $\mathrm{N}$ atoms can also inhibit the shuttle effect. When the annealing temperature is $600{ }^{\circ} \mathrm{C}$, the sulfur composite exhibits a good cycling stability and rate performance. The cathode showed an improved initial specific capability of 1042 and still maintained $477 \mathrm{mAh} \mathrm{g}^{-1}$ at the rate of $1 \mathrm{C}$ $\left(1 \mathrm{C}=1672 \mathrm{~mA} \mathrm{~g}^{-1}\right)$. Furthermore, at $5 \mathrm{C}$, a stable specific discharge capacity of $608 \mathrm{mAh} \mathrm{g}^{-1}$ was obtained.
\end{abstract}

Keywords: Li-S batteries; graphitic carbon; ZIF-67

\section{Introduction}

With the rapid development of electric vehicles and portable electronic equipment, the demand for batteries' storage and discharge capacity becomes higher. However, lithium-ion batteries, which are currently extremely widely used, can achieve limited improvement in capacity and energy density [1]. In contrast, lithium-sulfur (Li-S) batteries have a much higher theoretical specific capacity (1672 $\mathrm{mAh} \mathrm{g}^{-1}$ ) and energy density $\left(2600 \mathrm{Wh} \mathrm{kg}^{-1}\right)$ [2-4]. Additionally, sulfur is environmentally benign and abundant on the Earth [5,6], making Li-S batteries a potential commercial battery system [7-9]. However, such batteries still face various challenges that need to be addressed [10,11]. First, sulfur and lithium sulfide are insulating materials, resulting in poor conductivity which affects the rate performance. Second, the significant difference in the densities of sulfur and lithium sulfide causes large volume changes during cycling, which damages the electrode materials. In addition, the formed discharge intermediate, namely, lithium polysulfide (LiPS), can be dissolved in the electrolyte, which will increase the viscosity of the electrolyte and reduce its conductivity, on the one hand; on the other hand, the LiPS will flow to the anode, which is called the shuttle effect, leading to the formation of lithium sulfide on the anode, reducing the utilization of sulfur. The above phenomena can adversely affect the battery performance, resulting in poor stability and a reduced cycle life [12-17].

To address the aforementioned problems, porous carbon-based nanomaterials have been considered as promising candidates as sulfur hosts because of their matrix, large number of pores and large specific surface area, exhibiting good conductivity, sufficient ion transport channels [18] and the adsorption of LiPS to restrict the shuttle effect [19]. 
An upcoming category of materials, which can be used to obtain porous carbon structures, is the metal-organic framework materials (MOFs) [20]. MOFs are materials consisting of uniform networks formed by the combination of metal ions or ion clusters with organic ligands. One type of zeolitic imidazolate framework, ZIF-67, is a Co-based MOF material that forms an inorganic porous structure with $\mathrm{Co}-\mathrm{N}-\mathrm{C}$ bridges on annealing in a protective atmosphere. The annealed material is essentially a carbon framework doped with $\mathrm{N}$ atoms, which can improve the conductivity, surface polarity and adsorption of LiPS, and Co nanoparticles, which can inhibit the shuttle effect by adsorbing LiPS and promoting its decomposition to short-chain $\mathrm{Li}_{2} \mathrm{~S} / \mathrm{Li}_{2} \mathrm{~S}_{2}$ [21,22]. Based on the different functionalities of the MOF material, ZIF-67 is advantageous as a sulfur-loading electrode of Li-S batteries.

In this work, ZIF-67 was carbonized at high temperature, and the composition and structural differences in the material before and after heat treatment were analyzed. The two materials were used as sulfur-loading electrodes to prepare Li-S batteries, and their performance was studied. The experimental results show that the material changes from a microporous structure to a mesoporous structure after heat treatment, which enhances the storage and adsorption capacity of the material. Secondly, the bare metal sites of the material can catalyze the electrochemical reaction to reduce the loss of battery capacity. In addition, the framework structure of the material changes from organic to graphite, which improves the conductivity of the material, reduces the internal resistance of the batteries and improves the performance of the batteries significantly.

\section{Experimental Section}

\subsection{Synthesis of ZIF-67 Nanocubes}

First, $20 \mathrm{mg}$ of hexadecyl trimethyl ammonium bromide (CTAB) and $730 \mathrm{mg}$ of $\mathrm{Co}\left(\mathrm{NO}_{3}\right)_{2} \cdot 6 \mathrm{H}_{2} \mathrm{O}$ were dissolved in $30 \mathrm{~mL}$ deionized water to obtain solution $\mathrm{A}$, and $11.3 \mathrm{~g}$ of 2-methylimidazole was dissolved in $150 \mathrm{~mL}$ deionized water to obtain solution B. Secondly, the above two solutions were mixed and then stirred for $1 \mathrm{~h}$. A uniform, purple-colored mixture was obtained, which was centrifuged to obtain the precipitate and then washed with deionized water twice, and ethanol twice. Finally, the substance was dried for $12-16 \mathrm{~h}$ to acquire ZIF-67 nanocubes.

\subsection{Preparation of $\mathrm{Co}-\mathrm{NC} 600$}

In order to maintain the nanocube shape after heat treatment, the ZIF-67 powder was annealed in a tubular furnace at $300^{\circ} \mathrm{C}$ at a heating rate of $5^{\circ} \mathrm{C} \mathrm{min}-1$, kept for $2 \mathrm{~h}$ under Ar flow, then heated at $600{ }^{\circ} \mathrm{C}$ for $2 \mathrm{~h}$ with the same heating rate and, finally, cooled naturally. The as-obtained black powder was named Co-NC600.

\subsection{Preparation of S/ZIF-67 and S/Co-NC600}

ZIF-67 and Co-NC600 were subjected to the same treatment, described as follows, to prepare the sulfur-hosting matrix materials for the cathode, namely, S/ZIF-67 and S/CoNC600, respectively. The powder was mixed with sublimated sulfur powder according to a mass ratio of 1:3 and ground for $30 \mathrm{~min}$. Then, a small amount of $\mathrm{CS}_{2}$ solution was added to allow the sulfur to be fully dissolved, and the mixture was ground until $\mathrm{CS}_{2}$ completely evaporated. The obtained powder was poured into a poly tetra fluoroethylene (PTFE) hydrothermal reactor filled with argon and then sealed. Finally, the reactor was put in a constant temperature drying oven, at $155^{\circ} \mathrm{C}$ for $12 \mathrm{~h}$, to yield the required matrix material incorporated with sulfur.

\subsection{Material Characterization}

X-ray diffraction (XRD) patterns were obtained by (Bruker D8 Karlsruhe, Germany) diffractometer equipped with a $\mathrm{Cu}-\mathrm{Ka}$ radiation source. The structural details of the microstructure were obtained by a field-emission scanning electron microscope (FE-SEM, Hitachi S-4800, Tokyo, Japan) combined with energy-dispersive spectroscopy (EDS) and a high-resolution transmission electron microscope (HRTEM, JEM-2100F, JEOL, Tokyo, 
Japan). The $\mathrm{N}_{2}$ adsorption/desorption analysis was conducted using Micromeritics ASAP 2020 (Norcross, GA, USA), in order to measure the porosity and specific surface area at $77 \mathrm{~K}$. The elements and valence states of the products were analyzed by X-ray photoelectron spectroscopy (XPS, Thermo Fisher Scientific, ESCALAB 250Xi, Waltham, MA, USA). Thermogravimetric analysis (TGA, PerkinElmer, Series 7, Waltham, MA, USA) was carried out to reveal the weight content of sulfur in S/Co-NC600 at a heating rate of $10^{\circ} \mathrm{C} \mathrm{min}^{-1}$ in Ar flow.

\subsection{Electrochemical Measurements}

CR2032 coin-type cells were used to implement the electrochemical studies, where S/ZIF-67 and S/Co-NC600 were used as cathodes, and lithium foils were used as anodes. The electrolyte employed was $1 \mathrm{M}$ lithium bis (trifluoromethane sulfonyl) imide (LiTFSI) in a mixed solvent which consisted of 1,2-dimethoxyethane (DME) and 1,3-dioxolane (DOL), with a volume ratio of 1:1, containing $1 \mathrm{wt} \% \mathrm{LiNO}_{3}$. A Celgard 2325 polypropylene membrane was used as the separator.

Electrode slurries of S/ZIF-67 and S/Co-NC600 were produced by mixing S/ZIF-67 or S/Co-NC600, polyvinylidene fluoride (PVDF) binder and conductive carbon black (80\%:10\%:10\%) in N-methyl pyrrolidinone (NMP) solvent. After stirring for $30 \mathrm{~min}$, the slurry was evenly daubed onto Al foil and dried at $60{ }^{\circ} \mathrm{C}$ for $12 \mathrm{~h}$. The charge/discharge performance and cycle life of the cells were evaluated on a Neware battery tester between 1.7 and $2.8 \mathrm{~V}$. The cyclic voltammetry $(\mathrm{CV})$ and electrochemical impedance spectroscopy (EIS) measurements were performed using an electrochemical workstation (Princeton Applied Research, Versa STAT4, Princeton, NJ, USA).

\section{Results and Discussion}

Scanning electron microscopy (SEM) images of ZIF-67 and Co-NC600 are shown in Figure $1 \mathrm{a}, \mathrm{b}$, respectively. It can be found that the surface of ZIF-67 in Figure 1a is smooth, and there is also a uniform particle size of about $300 \mathrm{~nm}$. The nanocube morphology is different from the conventional dodecahedron because of the addition of CTAB, which changes the growth rate of different surfaces through adsorption on hydrophobic surfaces [23]. In contrast to the ZIF-67 nanocubes, the morphology of Co-NC600 changes slightly, as shown in Figure 1b. The cracking and crosslinking of organic ligands occur due to the heat treatment, which causes a certain degree of depression on the surface of Co-NC600 [24]. Figure 1c shows the TEM image of Co-NC600, which reveals a large number of large-sized pores compared with ZIF-67 shown in Figure S1, possibly due to the splitting of organic ligands. The HRTEM image is shown in Figure $1 \mathrm{~d}$, where two types of lattice fringes can be found in the red square and the blue square. The fast Fourier transformation (FFT) patterns of the squares are shown in Figure S2, in which there are many pairs of centrosymmetric light points, proving the existence of the crystal planes. Figure 1e shows that the applied masked points circled in Figure S1 and Figure 1f,g are the inverse FFT lattice images and the lattice spacing contours of Figure 1e. By such figures, it can be measured that two types of layer spacing of $0.340 \mathrm{~nm}$ in the red square and $0.177 \mathrm{~nm}$ in the blue square of Figure $1 \mathrm{~d}$ correspond to the (002) crystal face of carbon and the (200) crystal plane of cobalt metal, respectively. It can be found in Figure $1 \mathrm{~d}$ that Co nanoparticles are inset in the graphitic carbon framework. The high-magnification elemental maps of Co-NC600 are shown in Figure 1h. It can be seen that Co, C and N are evenly distributed onto the nanocubes. Thus, the organic ligands were annealed to form N-doped graphitic carbon frameworks in which the Co nanoparticles were uniformly embedded. The SEM image of S/Co-NC600 and the corresponding elemental mappings in Figure S3 clearly reveal the homogeneous distribution of C, Co and S elements, and that sulfur is well confined in the Co-NC600 nanocubes. 


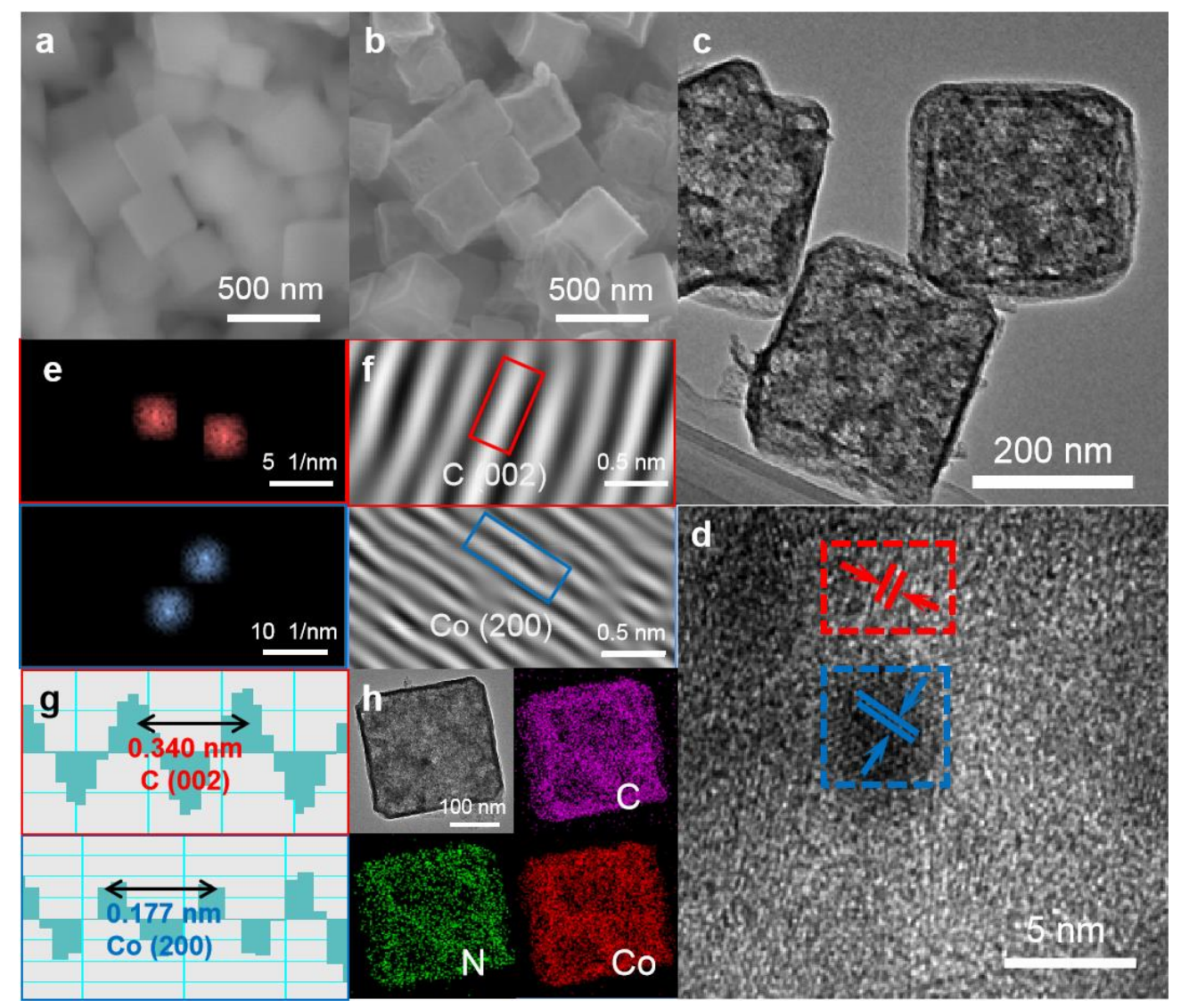

Figure 1. SEM images of (a) ZIF-67 and (b) Co-NC600; (c) TEM image and (d) HRTEM image of Co-NC600; (e) applied masked points of FFT patterns; (f) inverse FFT lattice images of (e); (g) the lattice spacing contour of Co-NC600; (h) elemental mapping of Co-NC600.

The XRD patterns of ZIF-67 and Co-NC600 are shown in Figure 2a. In the pattern of ZIF-67, the sharp peak at 7.2 ${ }^{\circ}$ indicates that the prepared ZIF-67 nanocubes have good crystallinity [25]. In the pattern of Co-NC600, there are three distinct peaks at $44.2^{\circ}, 51.5^{\circ}$ and $75.8^{\circ}$, which correspond to the characteristic peaks of the $\left(\begin{array}{lll}1 & 1 & 1\end{array}\right),\left(\begin{array}{lll}2 & 0 & 0\end{array}\right)$ and $(220)$ crystal planes of the metal Co, suggesting that when annealed at $600{ }^{\circ} \mathrm{C}$, the metallic Co particles are exposed. XPS was used to analyze the chemical composition of Co-NC600, whose N, C and Co element XPS spectra are shown in Figure $2 b-d$. As it is shown in the C 1 s spectrum of Figure $2 b$, it can be found that there are four types of carbon bonds, which correspond to $\mathrm{C}-\mathrm{C}$ at $284.5 \mathrm{eV}, \mathrm{C}-\mathrm{N}$ at $285.1 \mathrm{eV}, \mathrm{C}-\mathrm{O}$ at $286.0 \mathrm{eV}$ and $\mathrm{C}=\mathrm{O}$ at $288.2 \mathrm{eV}$. From the high-resolution $\mathrm{N}$ 1s spectrum, it can be seen that there are three types of $\mathrm{N}$ peaks, i.e., pyridinic $\mathrm{N}$ at $398.5 \mathrm{eV}$, pyrrolic $\mathrm{N}$ at $399.2 \mathrm{eV}$ and graphitic $\mathrm{N}$ at $400.7 \mathrm{eV}[24,26,27]$. The vacancy and defect sites due to $\mathrm{N}$ doping tend to promote the adsorption of LiPS on the porous material and enhance the reaction kinetics. In addition, the Co 2 p spectra of Co-NC600 have four peaks, which, at $779.2 \mathrm{eV}$ and $795.1 \mathrm{eV}$, correspond to the main peaks of Co $2 p_{3 / 2}$ and Co $2 p_{1 / 2}$, respectively, and the other peaks at $784.8 \mathrm{eV}$ and $801.2 \mathrm{eV}$ are the satellite peaks of the above two peaks, respectively. The analysis shows that both main peaks consist of $\mathrm{Co}\left(778.6 \mathrm{eV}\right.$ of $2 \mathrm{p}_{3 / 2}$ and $794.4 \mathrm{eV}$ of $\left.2 \mathrm{p}_{1 / 2}\right)$ and $\mathrm{Co}^{2+}(780.5 \mathrm{eV}$ for $2 \mathrm{p}_{3 / 2}$ and $796.1 \mathrm{eV}$ for $2 \mathrm{p}_{1 / 2}$ ) peaks. The existence of the $\mathrm{Co}^{2+}$ signal is mainly due to the nano-sized Co exposed on the surface of the materials that is partially oxidized by air. The presence of nano-sized transition metals can also enhance the adsorption and catalytic capabilities of the materials. 
a

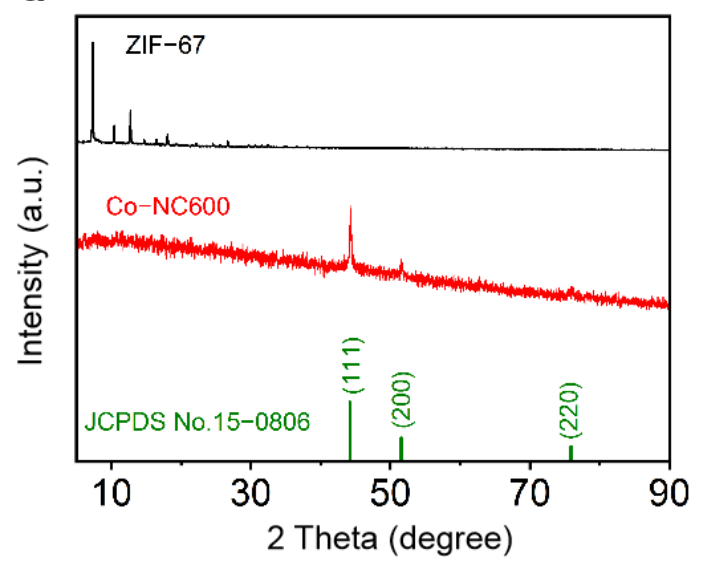

C

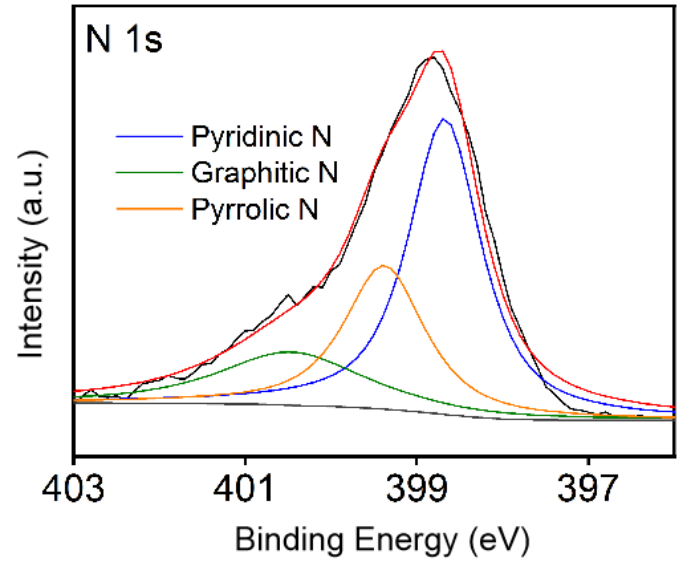

b

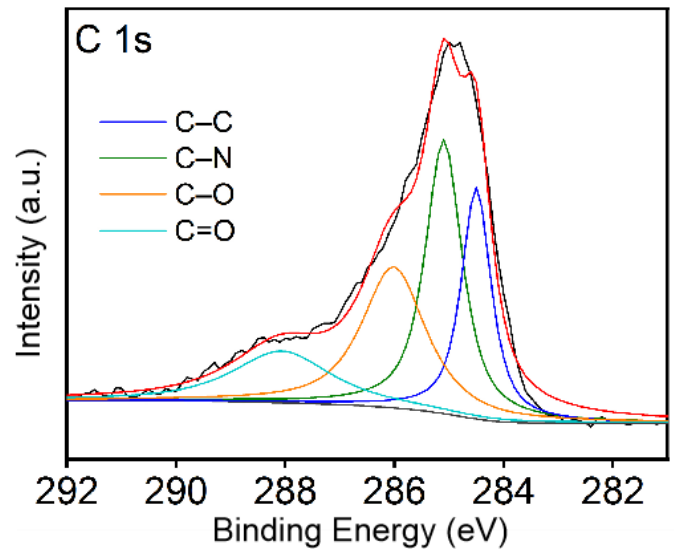

d

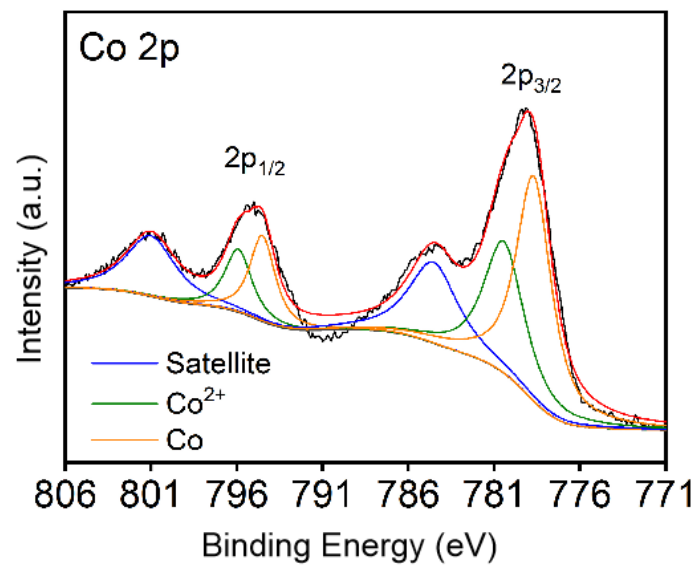

Figure 2. (a) XRD pattern of ZIF-67 and Co-NC600; XPS spectra of (b) C 1s, (c) N 1s and (d) Co 2p for Co-NC600.

The as-prepared S/Co-NC600 powders were analyzed by TGA, as shown in Figure 3a. When the temperature increases from 150 to $330^{\circ} \mathrm{C}$, the reference sulfur powder sublimates and almost completely disappears, while the mass of S/Co-NC600 reduces to only $29.8 \%$. XPS tests of S/Co-NC600 after annealing were performed to prove that sulfur does not remain in the material during the TGA process, as shown in Figure S4. The above results suggest that the mass proportion of sulfur in the prepared S/Co-NC600 is $70.2 \%$, which reveals that $\mathrm{Co}-\mathrm{NC} 600$ has a good sulfur loading capacity. Compared with S/Co-NC600, the mass of S/ZIF-67 decreases to $35.1 \%$ in the same temperature range, indicating that the mass proportion of sulfur in S/ZIF-67 is $64.9 \%$. It is not difficult to see that Co-NC600 has a better sulfur content than ZIF-67.

Figure $3 b$ shows the $\mathrm{N}_{2}$ adsorption/desorption isotherms of ZIF-67 and Co-NC600. The ZIF-67 nanocubes have a high Brunauer-Emmett-Teller (BET) surface area of $1672 \mathrm{~m}^{2} \mathrm{~g}^{-1}$, while, in comparison, the surface area of Co-NC600 is $266 \mathrm{~m}^{2} \mathrm{~g}^{-1}$. After annealing ZIF- 67 , the BET surface area was significantly reduced, mainly due to the gradual disappearance of the microporous structure in the nanocubes and the formation of a more mesoporous structure, which can be confirmed in Figure 3c. The average pore diameter of Co-NC600 was observed to be $7.67 \mathrm{~nm}$, which was much larger than that of ZIF-67 $(1.62 \mathrm{~nm})$.

The ability to capture polysulfides was visualized by a static adsorption test. A typical type of LiPS was used in the test, namely, $\mathrm{Li}_{2} \mathrm{~S}_{6}$. Figure $3 \mathrm{~d}$ shows a pristine $\mathrm{Li}_{2} \mathrm{~S}_{6}$ solution, along with the adsorption results of the $\mathrm{Li}_{2} \mathrm{~S}_{6}$ solution with ZIF-67 and Co-NC600. After the mixtures were left for $12 \mathrm{~h}$ to allow adsorption, the color of the mixture containing Co-NC600 was the lightest, the mixture containing ZIF-67 was lighter than before and the reference showed no color change. The results show that Co-NC600 was more effective at adsorbing $\mathrm{Li}_{2} \mathrm{~S}_{6}$ than ZIF-67. UV-Vis spectra further confirmed such a conclusion. As it 
is shown in Figure $3 d$, the solution containing Co-NC600 shows the lowest $\mathrm{Li}_{2} \mathrm{~S}_{6}$-related absorbance peak. This indicates that the amount of $\mathrm{Li}_{2} \mathrm{~S}_{6}$ in the supernatant of the CoNC600 addition was the lowest, which proves that Co-NC600 had better LiPS adsorption. Co-NC600 is better than ZIF-67 in adsorbing LiPS, firstly because the larger pore structure makes the material more capable of catching LiPS, and secondly because the exposed metal Co nanoparticles in the material interact strongly with LiPS, which anchors LiPS.

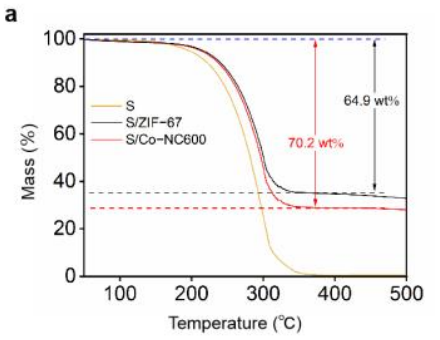

d

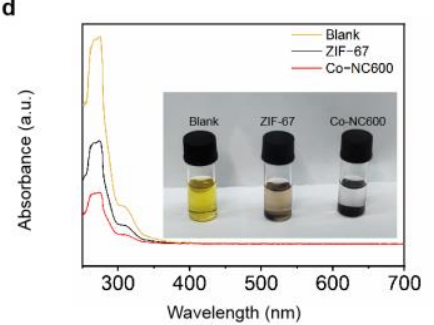

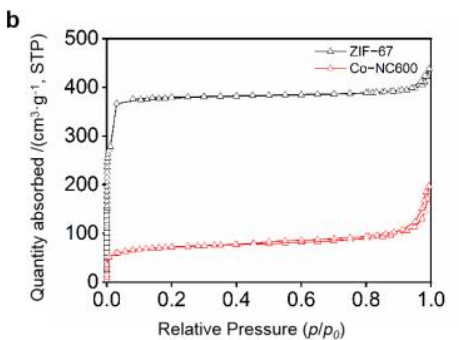

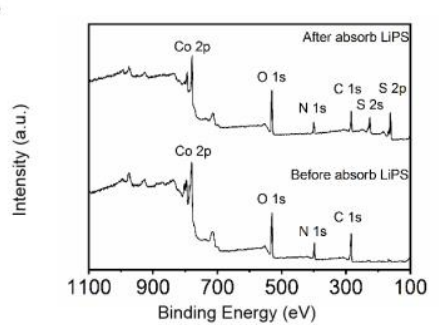

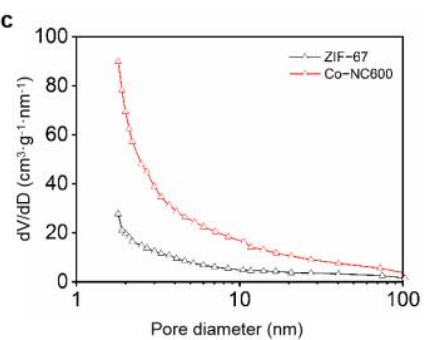

f

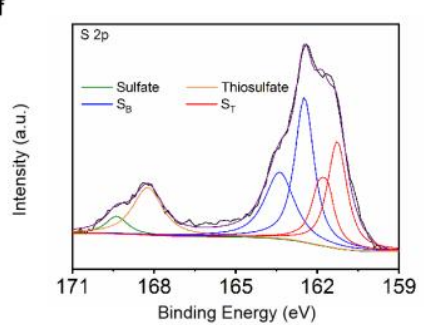

Figure 3. (a) TGA curves of $\mathrm{S}$ powder and S/Co-NC600; (b) $\mathrm{N}_{2}$ adsorption/desorption isotherms; (c) pore size distributions of ZIF-67 and Co-NC600; (d) UV-Vis spectra of $\mathrm{Li}_{2} \mathrm{~S}_{6}$ (pristine, with ZIF-67 and Co-NC600), where inset shows the corresponding photograph after $12 \mathrm{~h}$, ZIF-67 and Co-NC600; (e) XPS spectra of Co-NC600 before and after $\mathrm{Li}_{2} \mathrm{~S}_{6}$ adsorption and (f) S 2p spectra of Co-NC600 after $\mathrm{Li}_{2} \mathrm{~S}_{6}$ adsorption.

Figure 3e shows the XPS spectra of Co-NC600 before and after $\mathrm{Li}_{2} \mathrm{~S}_{6}$ adsorption. The appearance of the $S 2 \mathrm{p}$ peak proves the existence of adsorbed polysulfides. Figure $3 \mathrm{f}$ shows the detailed S 2p spectrum in the XPS spectra of Co-NC600 after $\mathrm{Li}_{2} \mathrm{~S}_{6}$ adsorption, where the two pairs of peaks at 161.2 and $163.0 \mathrm{eV}$ are attributed to the terminal sulfur $\left(\mathrm{S}_{\mathrm{T}}\right)$ and bridging sulfur $\left(\mathrm{S}_{\mathrm{B}}\right)$, respectively. The peaks appearing at 169.4 and $168.2 \mathrm{eV}$ illustrate the formation of sulfate and thiosulfate, indicating that the metal Co can react with LiPS chemically, and Co-NC600 has the ability of chemisorption of LiPS.

The electrochemical properties of S/Co-NC600 cathodes were tested, which can be seen in Figure 4. The cyclic voltammogram (CV) curves of the S/Co-NC600 electrodes are shown in Figure $4 \mathrm{a}$. The scanning speed was set to $1 \mathrm{mV} \mathrm{s}^{-1}$ for three cycles at the range from 1.7 to $2.8 \mathrm{~V}$. The $\mathrm{CV}$ shows two related reduction peaks near 2.3 and $2.0 \mathrm{~V}$ during discharge, which correspond to the reduction of sulfur to long-chain polysulfide $\left(\mathrm{Li}_{2} \mathrm{~S}_{\mathrm{x}}\right.$, $4 \leq \mathrm{x} \leq 8$ ) and the further reduction of polysulfide to $\mathrm{Li}_{2} \mathrm{~S}_{2} / \mathrm{Li}_{2} \mathrm{~S}$. In the anodic sweep, the oxidation peaks at $2.4 \mathrm{~V}$ correspond to the oxidation of $\mathrm{Li}_{2} \mathrm{~S} / \mathrm{Li}_{2} \mathrm{~S}_{2}$ to $\mathrm{Li}_{2} \mathrm{~S}_{8}$. It is obvious that the three cycle curves almost coincide, which shows that the electrodes have a good electrochemical performance and cycle stability.

Figure $4 b, c$ show the constant current charge/discharge curves of the S/ZIF-67 and S/Co-NC600 electrodes at a rate of $0.2 \mathrm{C}\left(1 \mathrm{C}=1672 \mathrm{~mA} \mathrm{~g}^{-1}\right)$, respectively. The initial specific discharge and charge capacities of the S/ZIF-67 electrode are 968 and $1033 \mathrm{mAh} \mathrm{g}^{-1}$, and after 100 cycles, the specific capacities decrease to 478 and $492 \mathrm{mAh} \mathrm{g}^{-1}$, respectively. In contrast, the S/Co-NC600 electrode has a higher specific capacity, with initial specific discharge and charge capacities of 1237 and $1228 \mathrm{mAh} \mathrm{g}^{-1}$, which decrease to 782 and $796 \mathrm{mAh} \mathrm{g}^{-1}$ after 100 cycles. The S/Co-NC600 electrode demonstrates a higher specific capacity than the S/ZIF-67 electrode. Similar to other reports of sulfur-based cathodes, the curves have two platforms corresponding to two reduction reactions in all discharge 
processes of the S/Co-NC600 electrode. During the cycle test, the good overlap of the discharge plateau also shows that the electrode has good stability and reversibility.

a
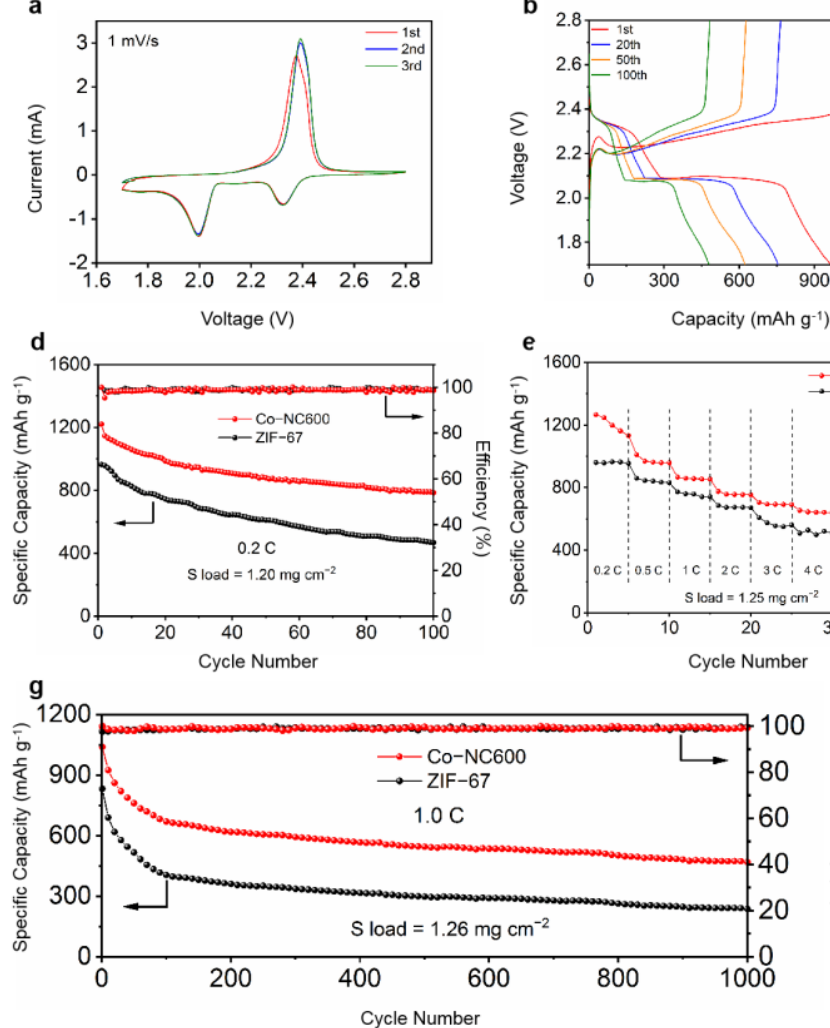
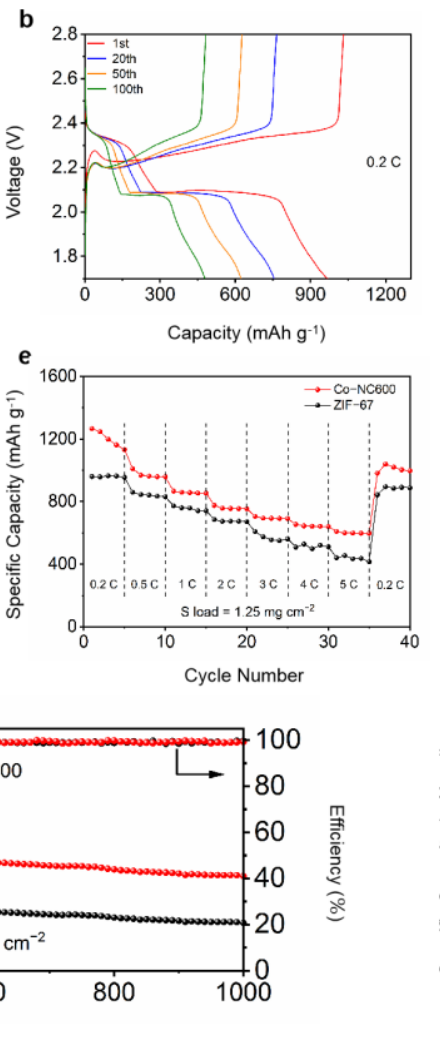
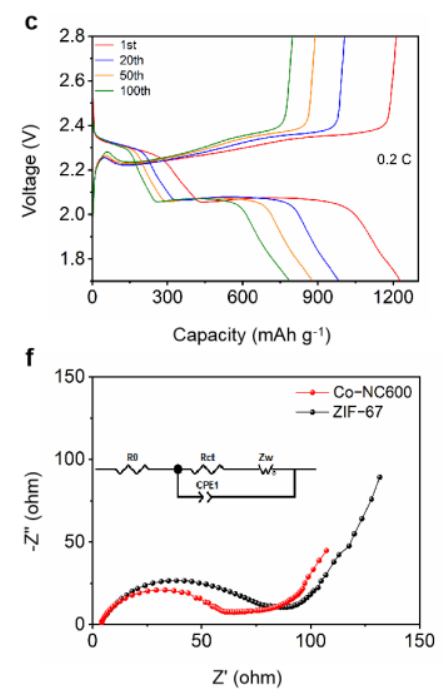

h

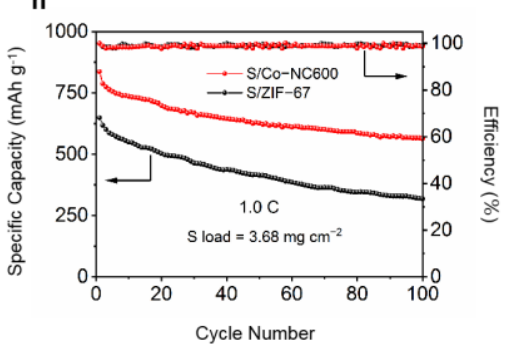

Figure 4. (a) CV curves of the cells with the S/Co-NC600 electrode; charge/discharge profiles of (b) S/ZIF-67 and (c) CoNC600 electrodes; (d) cycling performances of S/ZIF-67 and S/Co-NC600 electrodes; (e) rate performances of S/ZIF-67 and S/Co-NC600 electrodes; (f) EIS spectra of cells with the cathodes of S/ZIF-67 and S/Co-NC600, where the inset is the equivalent circuit used to fit the impedance spectrum; (g) long-term cycling performances of S/ZIF-67 and S/Co-NC600; and (h) cycling performances of high-sulfur loading electrodes. The meaning of arrow in $\mathrm{d}, \mathrm{g}$ and $\mathrm{h}$ is to show what the ordinate of the corresponding curve means. The left arrow represents the specific capacity and the right arrow represent efficiency of the curves.

The cycling performances of the two types of electrodes were tested at $0.2 \mathrm{C}$ by constant current charge/discharge measurements. In Figure $4 \mathrm{~d}$, after 100 cycles, the capacity retention rate is $63 \%$. Such results are better than those of the S/ZIF-67 electrode under the same experimental conditions (the capacity retention rate is $49 \%$ ), thus demonstrating that S/Co-NC600 has a higher sulfur utilization rate. This is because the metal Co can hold LiPS to inhibit the shuttle effect and reduce the loss of sulfur.

Figure $4 \mathrm{e}$ shows the rate capability test of the two electrodes. When the current density increases from 0.2 to $5.0 \mathrm{C}$, the specific discharge capacity of S/Co-NC600 changes from 1216 to $608 \mathrm{mAh}^{-1}$. On the other hand, the specific discharge capacity of the S/ZIF-67 electrode changes from 960 to $441 \mathrm{mAh}^{-1}$. Thus, the S/Co-NC600 electrode showed a better electrochemical performance than the S/ZIF-67 electrode. Moreover, when the current rate is restored to $0.2 \mathrm{C}$, the specific discharge capacity of the S/Co-NC600 electrode can still reach $1033 \mathrm{mAh} \mathrm{g}^{-1}$, indicating that the electrode demonstrated a good recovery. Such properties can be attributed to the structural properties and material composition of Co-NC600. Annealing treatment at high temperatures results in a higher mesopore content, which renders the porous matrix better at sulfur storage and facilitates ion conduction. The exposed metal active sites can also adsorb LiPS to significantly suppress the shuttle effect, which enhances the performance of the batteries. 
Figure $4 \mathrm{f}$ shows the EIS spectra of the two types of batteries, and the inset is the equivalent circuit, in which $R_{c t}, Z_{W}$, constant phase angle element (CPE) and $R_{0}$ stand for the charge transfer resistance, ionic transport resistance, constant phase angle element and other resistance, respectively. The semicircles at the high frequency in the EIS spectra represent $R_{c t}$, while the approximate straight lines at the low frequency correspond to $Z_{\mathrm{W}}$ [28]. Compared with the EIS spectra of the S/ZIF-67 electrode, the S/Co-NC600 electrode has a smaller radius semicircle, which means the $R_{c t}$ of the $S / C o-N C 600$ electrode is smaller. The electrode resistance data obtained from the equivalent circuit in Table S1 can also prove such a conclusion. This implies that the charge transfer at the S/Co-NC600 electrode/polysulfide interface is faster, indicating that Co-NC600 efficiently converts LiPS. In addition, the S/Co-NC600 electrode also has a smaller $\mathrm{Z}_{\mathrm{W}}$, which indicates that the suitable enlarged pore structure can make ion transmission more convenient.

For Li-S battery applications, long-term cycle stability and good capacity retention are critical requirements. The batteries composed of the S/ZIF-67 and S/Co-NC600 electrodes were charged and discharged for 1000 cycles at the rate of $1.0 \mathrm{C}$. As it is shown in Figure $4 \mathrm{~g}$, S/Co-NC600 exhibits an initial specific discharge capacity of $1042 \mathrm{mAh} \mathrm{g}^{-1}$ and maintains this at $477 \mathrm{mAh} \mathrm{g}^{-1}$ after 1000 cycles. The capacity retention rate is $46 \%$, and the average capacity decay rate per cycle is $0.06 \%$. Compared with the S/Co-NC600 electrode, the S/ZIF-67 electrode has a specific discharge capacity of $827 \mathrm{mAh} \mathrm{g}^{-1}$ at the first cycle, and after 1000 cycles, the specific discharge capacity is $237 \mathrm{mAh} \mathrm{g}^{-1}$, whose capacity retention rate is $29 \%$. Compared with S/ZIF-67, S/Co-NC600 had a higher specific capacity and better cycling stability.

Co-NC600 has a better electrochemical performance, which benefits from its unique structure. First, Co-NC600 contains more mesopores which are conducive to the adsorption of LiPS, the loading of sulfur and the transport of ions and electrolytes. Secondly, the exposed Co nanoparticles on the carbon frameworks play a very important role in the adsorption of LiPS, which suppresses the shuttle effect. The metal nanoparticles can also greatly enhance the redox reaction kinetics of polysulfides through electrocatalysis. In addition, the doped $\mathrm{N}$ atoms induce more active defect sites, which are conducive to a better fixation of polysulfide, thereby effectively suppressing the polysulfide shuttle effect.

Considering the critical importance of sulfur loading of the cathode in practical applications, the cycle performance of the S/Co-NC600 electrode, at a higher sulfur loading, was measured. A coin cell with a sulfur load of $3.68 \mathrm{mg} \mathrm{cm}^{-2}$ was assembled and measured for 100 cycles, at the current rate of 1 C. It can be seen in Figure 4 h that the initial specific discharge capacity of the battery is $838 \mathrm{mAh} \mathrm{g}^{-1}$, which then decreases to $592 \mathrm{mAh} \mathrm{g}^{-1}$ after 100 cycles, and the capacity retention rate is $71 \%$. Inevitably, batteries with a higher sulfur load usually suffer from more severe shuttle effects and higher electrochemical polarization, which will lead to a lower sulfur utilization, faster capacity decay and worse cycling stability. Capacity decay was observed in the first three cycles, which may be related to the low sulfur utilization and an increase in the sulfur density. After three cycles, the S/Co-NC600 electrode exhibited high coulombic efficiency, indicating a highly stable performance. The results further reveal that the porous structure and the presence of $\mathrm{N}$ atoms and Co nanoparticles were highly conducive to the adsorption and catalysis of polysulfides.

The electrochemical properties of S/Co-NC600 were compared with those of S/ZIFderived materials reported in the literature, whose results are summarized in Table 1 . The proper structured S/Co-NC600 electrode consisting of porous carbon frameworks and plenty of metal nanoparticles shows an excellent initial capacity. Of note, some reported ZIF materials can form regular structures on a larger scale by compounding with conductive carbon materials (CNT, rGO, etc.), which further enhances the ability of sulfur carrying and LiPS adsorption and ultimately improves the performance of Li-S batteries. This provides a new idea for improving the specific capacity and stability of S/Co-NC600 electrodes. 
Table 1. The performance of various ZIF-derived materials as sulfur-carrying materials reported in the literature.

\begin{tabular}{cccccc}
\hline $\begin{array}{c}\text { Sulfur-Carrier } \\
\text { Materials }\end{array}$ & $\begin{array}{c}\text { Current } \\
\text { Rate }\end{array}$ & $\begin{array}{c}\text { Initial Discharge } \\
\text { Capacity }\left(\mathbf{m A h ~ g}^{-1}\right)\end{array}$ & $\begin{array}{c}\text { Cycle } \\
\text { Number }\end{array}$ & $\begin{array}{c}\text { Average } \\
\text { Capacity Decay } \\
\text { Rate (\%) }\end{array}$ & Reference \\
\hline Co-NC600 & $1 \mathrm{C}$ & 1042 & 1000 & 0.06 & In this work \\
\hline ZIF-8@3DC & $1 \mathrm{C} / 3 \mathrm{C}$ & 1098 & $200 / 800$ & $0.04(3 \mathrm{C})$ & {$[29]$} \\
\hline CNTs/Co $\mathrm{S}_{4} @ \mathrm{NC}$ & $5 \mathrm{C}$ & 850 & 1000 & 0.0137 & {$[30]$} \\
\hline 3DOM ZIF-8 & $2 \mathrm{C}$ & 802 & 500 & 0.028 & {$[31]$} \\
\hline ZIF-8@rGO & $1 \mathrm{C}$ & 678 & 300 & - & {$[32]$} \\
\hline ZIF-67-PPy & $0.1 \mathrm{C}$ & 1093 & 200 & - & {$[33]$} \\
\hline Z-CoS 2 & $1 \mathrm{C}$ & $\sim 920$ & 1000 & 0.04 & {$[34]$} \\
\hline HZIF/CNT & $0.5 \mathrm{C}$ & 986 & 500 & 0.073 & {$[35]$} \\
\hline
\end{tabular}

To compare the electrocatalytic activities of Co-NC600 and ZIF-67, the diffusion rates of lithium ions in Li-S batteries with S/Co-NC600 and S/ZIF-67 electrodes were measured by $\mathrm{CV}$ tests at various scanning rates from 0.1 to $1 \mathrm{mV} \mathrm{s}^{-1}$, as shown in Figure 5. By observing and analyzing the results of Figure $5 \mathrm{a}, \mathrm{b}$, it can be found that the peak potential of the S/Co-NC600 electrode changes little with the increase in the scanning rate, and the peak potential of the S/ZIF-67 electrode changes more obviously, which shows that the cells with the S/Co-NC600 electrode have a more stable electrochemical performance. The comparison of the diffusion coefficients of lithium ions is based on the classical RandlesSevick equation:

$$
\mathrm{I}_{\mathrm{p}}=2.69 \times 10^{5} \mathrm{n}^{3 / 2} \mathrm{~A} \mathrm{D}_{\mathrm{Li}}^{1 / 2} \mathrm{v}^{1 / 2} \mathrm{C}_{\mathrm{Li}} \text { (at room temperature) }
$$

where $I_{p}$ is the peak current, $n$ is the number of charges involved in the reaction, $D_{L i}$ represents the diffusion coefficient of $\mathrm{Li}$ in the electrode, $\mathrm{v}$ is the scanning rate and $\mathrm{C}_{\mathrm{Li}}$ represents the concentration of $\mathrm{Li}^{+}$in the electrolyte. According to the formula, there is a linear relationship between $\mathrm{I}_{\mathrm{p}}$ and $\mathrm{v}^{1 / 2}$, and between $\mathrm{I}_{\mathrm{p}} / \mathrm{v}^{1 / 2}$ and $\mathrm{D}_{\mathrm{Li}}^{1 / 2}$. When the other parameters are the same, the larger the $\mathrm{I}_{\mathrm{p}} / \mathrm{v}^{1 / 2}$ value, the larger the $\mathrm{D}_{\mathrm{Li}}$ value, and the stronger the diffusion ability of lithium ions. The linear relationship between $I_{P}$ and $v^{1 / 2}$ in Figure $5 \mathrm{a}, \mathrm{b}$ was analyzed, as shown in Figure $5 \mathrm{c}$,d. It can be found that the values of $\mathrm{I}_{\mathrm{p}} / \mathrm{v}^{1 / 2}$ of the $\mathrm{S} / \mathrm{Co}-\mathrm{NC} 600$ electrode $\left(\mathrm{K}_{\mathrm{A}}=0.963, \mathrm{~K}_{\mathrm{B}}=0.398\right.$ and $\left.\mathrm{K}_{\mathrm{C}}=0.236\right)$ are obviously larger than those of $\mathrm{S} / \mathrm{ZIF}-67\left(\mathrm{~K}_{\mathrm{A}}=0.635, \mathrm{~K}_{\mathrm{B}}=0.390\right.$ and $\left.\mathrm{K}_{\mathrm{C}}=0.196\right)$. This result shows that the lithium ions in the batteries with S/Co-NC600 electrodes have a better diffusion ability.

The Warburg coefficient in the EIS test can be used to further calculate the lithium ion diffusion coefficient in the battery, as the following equation [36]:

$$
\mathrm{D}_{\mathrm{Li}}=1 / 2\left(\mathrm{RT} / \mathrm{An}^{2} \mathrm{~F}^{2} \mathrm{C} \sigma_{\mathrm{W}}\right)^{2}
$$

where $\mathrm{R}$ is the universal gas constant $\left(8.314 \mathrm{~J} \mathrm{~mol}^{-1} \mathrm{~K}^{-1}\right), \mathrm{T}$ is the room temperature $(298.15 \mathrm{~K}), \mathrm{A}$ is the area of the electrode surface, $\mathrm{n}$ is the number of electron(s) per molecule oxidized F is Faraday's constant $\left(96,500 \mathrm{C} \mathrm{mol}^{-1}\right), \mathrm{C}$ is the concentration of lithium ions and $\sigma_{\mathrm{w}}$ is the Warburg coefficient. $\sigma_{\mathrm{w}}$ can be measured by the slope of $Z^{\prime}$ (the real part of impedance) and $\omega$ (the angular frequency, $2 \pi \mathrm{f})^{-1 / 2}$ in the low-frequency region, as shown in Figure S5. Table 2 shows the value of $\sigma_{\mathrm{W}}$ and $\mathrm{D}_{\mathrm{Li}}$ in the S/ZIF-67 and S/Co-NC600 batteries. Compared with ZIF-67, Co-NC600 has a better ability to promote the diffusion of lithium ions, which can promote the redox process of lithium polysulfide to inhibit the shuttle effects. This is due to the exposed metal Co nanoparticles on the Co-NC600 surface, providing catalytic reaction sites. 

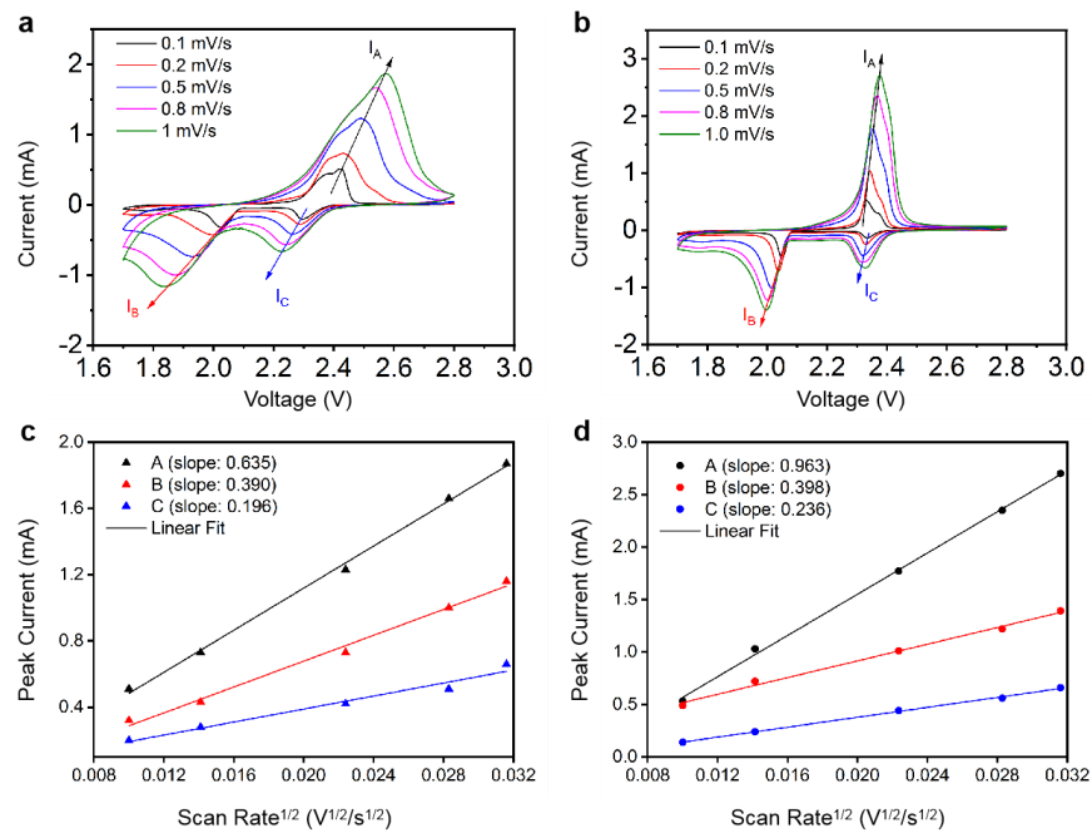

Figure 5. CV curves and corresponding linear fits of the peak currents of Li-S cells with (a,c) S/ZIF-67 cathode and (b,d) S/Co-NC600 cathode.

Table 2. The value of the lithium ion diffusion coefficient and Warburg coefficient in the two types of batteries.

\begin{tabular}{ccc}
\hline Sulfur-Carrier Materials & ZIF-67 & Co-NC600 \\
\hline$\sigma_{\mathrm{w}}\left(\Omega \mathrm{s}^{-1 / 2}\right)$ & 41.1 & 5.6 \\
\hline $\mathrm{D}_{\mathrm{Li}}\left(\mathrm{cm}^{2} \mathrm{~s}^{-1}\right)$ & $1.8 \times 10^{-15}$ & $1.9 \times 10^{-13}$ \\
\hline
\end{tabular}

\section{Conclusions}

Using ZIF-67 as a template, a Co and N-codoped graphitic carbon material (Co-NC600) was prepared by an annealing process, and both materials were used as cathode materials in Li-S batteries. The microscopic morphology, phase composition and pore structure of the material were analyzed by various measurement methods. Through various analyses, it was found that, compared with ZIF-67, Co-NC600 has conductive carbon frameworks, a larger pore structure and exposed metal nanoparticles. Carbon frameworks can improve the electrical conductivity of the material; an appropriately sized pore structure can improve the abilities of loading sulfur and adsorbing lithium polysulfides; and exposed metal nanoparticles can allow the material to carry on the chemical adsorption of the lithium polysulfides to impede the shuttle effect. Subsequently, the electrochemical performance of different electrodes was systematically studied. This work shows that the performance of the S/Co-NC600 composite electrode is significantly better. The specific discharge capacity in the first cycle at a current rate of $1 \mathrm{C}$ was $1042 \mathrm{mAh} \mathrm{g}^{-1}$ and remained at $477 \mathrm{mAh} \mathrm{g}^{-1}$ after 1000 cycles. Even at a high current density, at 5.0 C, a stable specific discharge capacity of $608 \mathrm{mAh} \mathrm{g}^{-1}$ can be attained.

Supplementary Materials: The following are available online at https://www.mdpi.com/article/ 10.3390/nano11081910/s1, Figure S1. TEM image of ZIF-67 nanocubes; Figure S2. FFT patterns of (a) red square and (b) blue square in the HRTEM image of Co-NC600; Figure S3. Elemental mapping of S/Co-NC600; Figure S4. XPS spectra of S/Co-NC600 after annealing at $350{ }^{\circ} \mathrm{C}$ under $\mathrm{Ar}$ flow; Figure S5. The liner fit between $Z^{\prime}$ and $\omega^{-1 / 2}$ in the batteries with S/ZIF-67 and S/Co-NC600 electrodes; Table S1. Electrode resistance data of S/ZIF-67 and S/Co-NC600 cathodes obtained from the equivalent circuit. 
Author Contributions: Formal analysis, S.N. and C.H.; investigation, S.N. and Y.L.; writing-original draft, S.N.; writing-review and editing, F.Y. and Y.Z.; supervision, F.Y.; project administration, Y.Z. All authors have read and agreed to the published version of the manuscript.

Funding: This work was supported by the Natural Science Foundation of Hebei Province of China (Grant No. B2019202277).

Data Availability Statement: No new data were created or analyzed in this study. Data sharing is not applicable to this article.

Conflicts of Interest: The authors declare no conflict of interest.

\section{References}

1. Wu, H.; Li, Y.; Ren, J.; Rao, D.; Zheng, Q.; Zhou, L.; Lin, D. CNT-assembled dodecahedra core@nickel hydroxide nanosheet shell enabled sulfur cathode for high-performance lithium-sulfur batteries. Nano Energy 2019, 55, 82-92. [CrossRef]

2. Bruce, P.G.; Freunberger, S.A.; Hardwick, L.J.; Tarascon, J.M. Li-O 2 and Li-S batteries with high energy storage. Nat. Mater. 2011, 11, 19-29. [CrossRef] [PubMed]

3. Han, K.S.; Chen, J.; Cao, R.; Rajput, N.N.; Murugesan, V.; Shi, L.; Pan, H.; Zhang, J.G.; Liu, J.; Persson, K.A.; et al. Effects of Anion Mobility on Electrochemical Behaviors of Lithium-Sulfur Batteries. Chem. Mater. 2017, 29, 9023-9029. [CrossRef]

4. Li, Z.; Wu, H.B.; Lou, X.W.D. Rational designs and engineering of hollow micro-/nanostructures as sulfur hosts for advanced lithium-sulfur batteries. Energy Environ. Sci. 2016, 9, 3061-3070. [CrossRef]

5. Nazar, L.F.; Cuisinier, M.; Pang, Q. Lithium-sulfur batteries. MRS Bull. 2014, 39, 436-442. [CrossRef]

6. Xu, J.; Zhang, W.X.; Chen, Y.; Fan, H.B.; Su, D.W.; Wang, G.X. MOF-derived porous N-Co $\mathrm{O}_{4} @ \mathrm{~N}-\mathrm{C}$ nanododecahedra wrapped with reduced graphene oxide as a high capacity cathode for lithium-sulfur batteries. J. Mater. Chem. A 2018, 6, $2797-2807$. [CrossRef]

7. Pope, M.A.; Aksay, I.A. Structural Design of Cathodes for Li-S Batteries. Adv. Energy Mater. 2015, 5, 1500124. [CrossRef]

8. Jin, Z.Q.; Xie, K.; Hong, X.B. Review of Electrolyte for Lithium Sulfur Battery. Acta Chim. Sin. 2014, 72, 11. [CrossRef]

9. Li, Z.; Yuan, L.X.; Yi, Z.Q.; Sun, Y.M.; Liu, Y.; Jiang, Y.; Shen, Y.; Xin, Y.; Zhang, Z.L.; Huang, Y.H. Insight into the Electrode Mechanism in Lithium-Sulfur Batteries with Ordered Microporous Carbon Confined Sulfur as the Cathode. Adv. Energy Mater. 2014, 4, 1301473. [CrossRef]

10. Li, F.Q.; Zhu, Z.H. Development of lithium/sulfur battery and its facing challenge. Chin. J. Power Sour. 2016, 5, 1142-1144.

11. Fotouhi, A.; Auger, D.J.; Propp, K.; Longo, S.; Wild, M. A review on electric vehicle battery modelling: From Lithium-ion toward Lithium-Sulphur. Renew. Sustain. Energy Rev. 2016, 56, 1008-1021. [CrossRef]

12. Huang, J.Q.; Zhang, Q.; Wei, F. Multi-functional separator/interlayer system for high-stable lithium-sulfur batteries: Progress and Prospects. Energy Storage Mater. 2015, 1, 127. [CrossRef]

13. Pan, H.L.; Han, K.S.; Vijayakumar, M.; Xiao, J.; Cao, R.G.; Chen, J.Z.; Zhang, J.G.; Mueller, K.T.; Shao, Y.Y.; Liu, J. Ammonium Additives to Dissolve Lithium Sulfide through Hydrogen Binding for High-Energy Lithium-Sulfur Batteries. ACS Appl. Mater. Interfaces 2017, 9, 4290-4295. [CrossRef] [PubMed]

14. Zhang, X.Q.; Cheng, X.B.; Zhang, Q. Nanostructured energy materials for electrochemical energy conversion and storage: A review. J. Energy Chem. 2016, 25, 967-984. [CrossRef]

15. Liu, D.; Zhang, C.; Zhou, G.; Lv, W.; Ling, G.; Zhi, L.; Yang, Q.H. Catalytic Effects in Lithium-Sulfur Batteries: Promoted Sulfur Transformation and Reduced Shuttle Effect. Adv. Sci. 2017, 5, 1700270. [CrossRef]

16. Bhattacharya, P.; Nandasiri, M.I.; Lv, D.P.; Schwarz, A.M.; Darsell, J.T.; Henderson, W.A.; Tomalia, D.A.; Liu, J.; Zhang, J.G.; Xiao, J. Polyamidoamine dendrimer-based binders for high-loading lithium-sulfur battery cathodes. Nano Energy 2016, 19, 176-186. [CrossRef]

17. Huang, C.; Xiao, J.; Shao, Y.Y.; Zheng, J.M.; Bennett, W.D.; Lu, D.P.; Saraf, L.V.; Engelhard, M.; Ji, L.W.; Zhang, J.G.; et al. Manipulating surface reactions in lithium-sulphur batteries using hybrid anode structures. Nat. Commun. 2014, 5, 1-8. [CrossRef] [PubMed]

18. Xu, Y.H.; Wen, Y.; Zhu, Y.J.; Gaskell, K.; Cychosz, K.A.; Eichhorn, B.; Xu, K.; Wang, C.S. Confined Sulfur in Microporous Carbon Renders Superior Cycling Stability in Li/S Batteries. Adv. Funct. Mater. 2015, 25, 4312-4320. [CrossRef]

19. Chong, W.G.; Huang, J.Q.; Xu, Z.L.; Qin, X.Y.; Wang, X.Y.; Kim, J.K. Lithium-Sulfur Battery Cable Made from Ultralight, Flexible Graphene/Carbon Nanotube/Sulfur Composite Fibers. Adv. Funct. Mater. 2017, 27, 1604815. [CrossRef]

20. Xia, W.; Mahmood, A.; Zou, R.Q.; Xu, Q. Metal-organic frameworks and their derived nanostructures for electrochemical energy storage and conversion. Energy Environ. Sci. 2015, 8, 1837-1866. [CrossRef]

21. Xia, Y.; Fang, R.Y.; Xiao, Z.; Huang, H.; Gan, Y.P.; Yan, R.J.; Lu, X.H.; Liang, C.; Zhang, J.; Tao, X.Y.; et al. Confining Sulfur in N-Doped Porous Carbon Microspheres Derived from Microalgaes for Advanced Lithium-Sulfur Batteries. ACS Appl. Mater. Interfaces 2017, 9, 23782-23791. [CrossRef]

22. Li, Y.J.; Fang, J.M.; Zhang, J.H.; Yang, J.F.; Yuan, R.M.; Chang, J.K.; Zheng, M.S.; Dong, Q.F. A Honeycomb-like Co@N-C Composite for Ultrahigh Sulfur Loading Li-S Batteries. ACS Nano 2017, 11, 11417-11424. [CrossRef] [PubMed] 
23. Hu, H.; Guan, B.Y.; Lou, X.W. Construction of Complex CoS Hollow Structures with Enhanced Electrochemical Properties for Hybrid Supercapacitors. Chem 2016, 1, 102-113. [CrossRef]

24. Park, S.K.; Kim, J.K.; Kim, J.H.; Kang, Y.C. Metal organic framework-templated hollow $\mathrm{Co}_{3} \mathrm{O}_{4}$ nanosphere aggregate/N-doped graphitic carbon composite powders showing excellent lithium-ion storage performances. Mater. Charact. 2017, 132, 320-329. [CrossRef]

25. Zhang, H.; Zhao, W.Q.; Zou, M.C.; Wang, Y.S.; Chen, Y.J.; Xu, L.; Wu, H.S.; Cao, A.Y. 3D, Mutually Embedded MOF@Carbon Nanotube Hybrid Networks for High-Performance Lithium-Sulfur Batteries. Adv. Energy Mater. 2018, 8, 1800013. [CrossRef]

26. Xu, Y.Z.; Wei, J.C.; Tan, L.C.; Yu, J.; Chen, Y.W. A Facile approach to $\mathrm{NiCoO}_{2}$ intimately standing on nitrogen doped graphene sheets by one-step hydrothermal synthesis for supercapacitors. J. Mater. Chem. A 2015, 3, 7121-7131. [CrossRef]

27. Lin, Z.Y.; Waller, G.H.; Liu, Y.; Liu, M.L.; Wong, C.P. 3D Nitrogen-doped graphene prepared by pyrolysis of graphene oxide with polypyrrole for electrocatalysis of oxygen reduction reaction. Nano Energy 2013, 2, 241-248. [CrossRef]

28. Ge, X.L.; Li, C.X.; Li, Z.Q.; Yin, L.W. Tannic acid tuned metal-organic framework as a high-efficiency chemical anchor of polysulfide for lithium-sulfur batteries. Electrochim. Acta 2018, 281, 700-709. [CrossRef]

29. Kang, X.; Di Bernardo, I.; Yang, H.L.; Torres, J.F.; Zhang, L. Metal-organic framework microdomains in 3D conductive host as polysulfide inhibitor for fast, long-cycle Li-S batteries. Appl. Surf. Sci. 2021, 535, 147680. [CrossRef]

30. Zhang, H.; Zou, M.C.; Zhao, W.Q.; Wang, Y.S.; Chen, Y.J.; Wu, Y.Z.; Dai, L.X.; Cao, A.Y. Highly Dispersed Catalytic Co3S4 among a Hierarchical Carbon Nanostructure for High-Rate and Long-Life Lithium-Sulfur Batteries. Acs Nano 2019, 13, 3982-3991. [CrossRef]

31. Cui, G.L. Li, G.R.; Luo, D.; Zhang, Y.G.; Zhao, Y.; Wang, D.R.; Wang, J.Y.; Zhang, Z.; Wang, X.; Chen, Z.W.; Three-dimensionally ordered macro-microporous metal organic frameworks with strong sulfur immobilization and catalyzation for high-performance lithium-sulfur batteries. Nano Energy 2020, 72, 104685.

32. Wang, J.H.; Gao, L.; Zhao, J.J.; Zheng, J.D.; Wang, J.; Huang, J.R. A facile in-situ synthesis of ZIF-8 nanoparticles anchored on reduced graphene oxide as a sulfur host for Li-S batteries. Mater. Res. Bull. 2021, 133, 111061. [CrossRef]

33. Geng, P.B.; Cao, S.; Guo, X.T.; Ding, J.W.; Zhang, S.T.; Zheng, M.B.; Pang, H. Polypyrrole coated hollow metal-organic framework composites for lithium-sulfur batteries. J. Mater. Chem. A 2019, 7, 19465-19470. [CrossRef]

34. Zhang, N.; Yang, Y.; Feng, X.R.; Yu, S.H.; Seok, J.; Muller, D.A.; Abruna, H.D. Sulfur encapsulation by MOF-derived CoS2 embedded in carbon hosts for high-performance Li-S batteries. J. Mater. Chem. A 2019, 7, 21128-21139. [CrossRef]

35. Wu, Z.L.; Wang, L.; Chen, S.X.; Zhu, X.M.; Deng, Q.; Wang, J.; Zeng, Z.L.; Deng, S.G. Facile and low-temperature strategy to prepare hollow ZIF-8/CNT polyhedrons as high-performance lithium-sulfur cathodes. Chem. Eng. J. 2021, 404, 126579. [CrossRef]

36. Cao, Q.; Zhang, H.P.; Wang, G.J.; Xia, Q.; Wu, Y.P.; Wu, H.Q. A novel carbon-coated $\mathrm{LiCoO}_{2}$ as cathode material for lithium ion battery. Electrochem. Commun. 2007, 9, 1228-1232. [CrossRef] 